\title{
Difference of background in research and clinical practice between USA and China
}

\author{
Yang Wen", Ling Deng", Linlang Guo \\ Department of Pathology Zhujiang Hospital, Southern Medical University, Guangzhou 510282, China \\ Contributions: (I) Conception and design: Y Wen; (II) Administrative support: L Deng; (III) Provision of study materials or patients: Y Wen; (IV) \\ Collection and assembly of data: L Deng; (V) Data analysis and interpretation: L Deng; (VI) Manuscript writing: All authors; (VII) Final approval of \\ manuscript: All authors. \\ "These authors contributed equally to this work. \\ Correspondence to: Linlang Guo. Professor, Department of Pathology Zhujiang Hospital, Southern Medical University, 253 Gongye Road, Guangzhou \\ 510282, China. Email: linlangg@yahoo.com.
}

\begin{abstract}
Malignant tumors continue to threaten people's lives, and the incidence and mortality of lung cancer are particularly high. Due to different ethnic and cultural backgrounds, China and the United States differ in the clinical treatment of lung cancer and related basic research. The discrepancies are mostly visible in the prevention of cancer, the approval of anticancer drugs, availability of medical insurance, structure of medical education, availability of research funds, and many other aspects By understanding these differences, China and the United States, as well as other nations, can learn from each other and make progress together, which will help to improve the outcomes of cancer therapy.
\end{abstract}

Keywords: Difference; lung cancer; clinical practice; medical insurance

Submitted Nov 30, 2019. Accepted for publication Mar 25, 2020.

doi: $10.21037 /$ jtd.2020.04.07

View this article at: http://dx.doi.org/10.21037/jtd.2020.04.07

\section{Introduction}

According to the World Health Organization (WHO) estimate from 2015, cancer is the leading cause of death among individuals younger than 70 years in 91 of the 172 countries from which the data were available (1). Lung cancer is the most common malignant tumor with the highest mortality rate (2). Finding the cure for cancer has always been a critical concern for researchers and the general public. The pathogenic factors of lung cancer are very complex, and differences in the incidence, mortality, and pathology of tumors exist between China and the United States. Several factors contribute to this discrepancy. The United States is a developed country and China is a developing country. In addition to economic factors, the differences in the treatment of tumors are also due to social, cultural, environmental, and multiple other conditions. Moreover, the development of lung cancer is affected by race, genetics, gender, diet, and smoking habits $(3,4)$.
Many aspects of the field of medicine differ between China and the United States. This review is focused mostly on the dissimilarities, and sometimes even contrasts, between these two countries in basic cancer research and treatment of this disease. Through the analysis of tumor prevention, tumor therapy, traditional Chinese medicine (TCM), medical insurance, medical education, and several other factors that affect clinical outcomes, China and the United States can engage in an exchange of experiences and ideas, and jointly overcome the challenges presented by cancer, improving the efficiency of tumor treatment.

\section{Clinical practice}

Several differences are present between China and the United States in the clinical approach to cancer therapy. They include the standards of treatment, treatment procedures, tumor prevention, marketing of anti-cancer drugs, and, in particular, the utilization of TCM. 
In China, patients can register for consultation directly. However, the therapy for cancer patients is provided mostly by large hospitals, while small hospitals are responsible for nutritional support during the course of the treatment. Current medical reform envisions an increase in medical investment in rural areas and the elimination of irrational regional disparities (5). In the United States, the privacy of patients' information is protected by law. Doctors are prohibited from discussing the patient's condition on public platforms. In China, the protection of the confidentiality of medical information must be improved.

Cancer prevention is critical for reducing the impact of this disease. In China, cancer screening is not universal, and in more than $80 \%$ of cases, the tumor is already in the advanced stage at the time of diagnosis. Frequently, it has metastasized and is difficult to cure. This is the most important reason for the high cancer mortality rate in China. Generally, the awareness of the importance of cancer prevention and cancer screening is not widespread. People in some areas do not have a habit of annual physical check-ups, not to mention that many cancers cannot be detected by routine physical examination at an early stage. In the United States, cancer screening is generally included in medical insurance. The hospitals and physician offices distribute information on early screening, and doctors educate people to promote the importance of awareness of early detection and early treatment (6). In addition, the development and availability of early cancer screening technologies such as mammography and colonoscopy have also contributed to the reduction in cancer mortality in USA.

The control of tobacco use in China is not welldeveloped, and the incidence of refractory lung cancer is high. Since the 1960s, the United States has carried out tobacco control campaigns and strictly implemented the WHO Framework Convention on Tobacco Control, resulting in a complete ban on smoking in public spaces. These strong measures resulted in a continuous decline in the number of American smokers over the past 40 years, and the mortality rate of lung cancer among American men has decreased by $45 \%$ from 1990 to 2015 . In contrast, China is the world's largest producer and consumer of tobacco. There are 300 million smokers who account for one-third of the total number of smokers worldwide and $44 \%$ of global tobacco consumption. At the same time, more than 700,000 new cases of lung cancer are reported in China every year, leading the world in this statistic (6).

The time necessary for the approval of new cancer drugs in China is too long. For example, a PD-1 inhibitor, an immunotherapeutic drug, has been officially approved by the China Food and Drug Administration (CFDA) 4 years after it was introduced in the United States. According to the statistics, $80 \%$ of new drugs available in 2008 have not been listed in China by 2013 .

The combination of traditional Chinese and Western medicine is a unique feature of cancer treatment methods in China, representing one of the important strategies for comprehensive cancer therapy. There are three characteristics of TCM: effectiveness, diversity, and durability. The combination of dialectical thinking and disease syndrome is an essential concept in TCM therapy. The Response Evaluation Criteria in Solid Tumors (RECIST) are no longer the only metric to evaluate the curative effect of cancer therapy. In TCM, the goal of the treatment is a comprehensive improvement of symptoms, quality of life, and mental and nutritional status of patients. In addition, TCM emphasizes the significance of internal and external treatment, as well as physical and psychological treatment. Like Western medicine, TCM also pays attention to cancer prevention (7).

\section{Medical insurance}

China has a population of nearly 1.4 billion, and $59.58 \%$ are urban residents. A unified national medical insurance service, established in 2019, provides equal benefits to both urban and rural residents. The national health insurance covers 1.2 billion people, bringing the national coverage rate close to $90 \%$. In the case of lung cancer, the most common type of cancer in China, approximately $70 \%$ of the cost of treatment can be reimbursed. Lung cancer therapy has been tremendously improved in the past 10 years, but most of the newly developed treatments are provided at the patients' own expense. In 2019, the National Health Insurance Agency announced the expansion of benefits to cover the cost of five lung cancer targeted drugs, including crizotinib, osimertinib, ceritinib, anlotinib, and afatinib. In addition to the reimbursement of the cost of treating lung cancer, certain cities also plan to include smoking cessation drugs in the list of drugs reimbursed by medical insurance. In the long run, this policy will help to reduce the number of smokers and the incidence of lung cancer. To supplement the national medical insurance, the Chinese people can also purchase their own commercial insurance to reimburse medical expenses outside the scope of nationally provided coverage. The direct medical expenses of lung cancer patients depend on the different treatment options, with 
the cost for surgical patients being significantly higher than for non-surgical patients. Moreover, the cost of different chemotherapy regimens varies markedly.

\section{Medical education system}

The differences in medical care between China and the United States are also reflected in the educational mechanism. In China, medical training is provided at the university level, and the undergraduate course lasts 5 years. Subsequently, students can pursue a master's degree in medicine and a doctorate in medicine, each of which takes typically 3 years. Compared with the United States, Chinese universities are more difficult to enter and easier to graduate. Reform has been introduced lately requiring the graduates of the medical education program to undergo standardized training for residents, usually for 3 years in China (8). Within the scope of the secondary discipline, the graduates participate in the work of the clinical departments corresponding to their major discipline and carry out comprehensive and systematic basic clinical work as a part of their training. If necessary, students can also participate in standardized training for specialists; the time is the same for each specialty. Only after this training, the individuals can be officially employed by the hospital. The medical education in China will benefit from efforts to enhance students' innovative thinking and clinical abilities, improving the quality of talents and ensuring better patient care.

\section{Medical research}

The differences between Chinese and American medical research are mainly reflected in the position of researchers, research directions, and the availability of research funds. In China, the title of a clinician is linked to performing research activities. In addition, a large proportion of the researchers are graduate students. In the United States, the salary of graduate students is the responsibility of their supervisors. In China, subsidies for graduate students are provided by the state. Considering the directions of research is a significant part of the output of medical research in the United States reaches the market, an aspect that is worth improving in China. In terms of basic science, due to the internationalization of modern platforms of social communication, the research directions are mostly similar in China and the United States, but some differences persist. Clinical studies in the United States are focused mostly on early cancer, while this area is less developed in China (9).
Both countries have invested significant financial resources in cancer research. The National Institutes of Health $(\mathrm{NIH})$, a part of the US Department of Health and Human Services is the primary governmental medical research institution in the United States and the most important source of funding for biomedical research. Although the US government attaches great importance to the investment in biomedical research, as reflected by the magnitude of centralized funding, most of the financial support comes from the industry. In China, scientific research funds for medical research come from various national plans, such as Plan 973, Plan 863 and others, from the Ministry of Science and Technology, funds from the National Natural Science Foundation of China, and funds from other branches of the government, for example, the Ministry of Health and Ministry of Education. Together, there are more than 10 types of funding channels (10). Therefore, due to the pressure of securing the funds, American scientific research is highly competitive, while in China, the process is highly stable.

\section{Conclusions}

The analysis of several aspects of the treatment of lung cancer indicates that the prevention of tumor development and its early detection is of utmost importance. The level of medical care and the professionalism of doctors are improving both in China and in the United States. The treatment of tumors depends on multiple pathological and economic factors. Additionally, psychotherapy, long-term care, and family support are all important elements affecting cancer therapy.

\section{Acknowledgments}

We thank Dr. Tomoya Kawaguchi and Dr. Philip C. Mack Based for inviting us to write this review article on Focused Issue "Ethnic Differences in Lung Cancer".

Funding: None.

\section{Footnote}

Provenance and Peer Review: This article was commissioned by the Guest Editors (Tomoya Kawaguchi and Phillip C. Mack) for the Series "Ethnic Difference in Lung Cancer" published in Fournal of Thoracic Disease. The article was sent for external peer review organized by the Guest Editors and the editorial office. 
Conflicts of Interest: All authors have completed the ICMJE uniform disclosure form (available at http://dx.doi. org/10.21037/jtd.2020.04.07). The series "Ethnic Difference in Lung Cancer" was commissioned by the editorial office without any funding or sponsorship. The authors have no other conflicts of interest to declare.

Etbical Statement: The authors are accountable for all aspects of the work in ensuring that questions related to the accuracy or integrity of any part of the work are appropriately investigated and resolved.

Open Access Statement: This is an Open Access article distributed in accordance with the Creative Commons Attribution-NonCommercial-NoDerivs 4.0 International License (CC BY-NC-ND 4.0), which permits the noncommercial replication and distribution of the article with the strict proviso that no changes or edits are made and the original work is properly cited (including links to both the formal publication through the relevant DOI and the license). See: https://creativecommons.org/licenses/by-nc-nd/4.0/.

\section{References}

1. Wang N, Liu S, Yang L, et al. Interpretation of the 2018 Global Cancer Statistics Report. Journal of Multidisciplinary Cancer Management (Electronic Version) 2019;5:87-97.

2. Yang L, Li LD, Chen YD, et al. Mortality time trends and the incidence and mortality estimation and projection for lung cancer in China. Chinese Journal of Lung Cancer

Cite this article as: Wen Y, Deng L, Guo L. Difference of background in research and clinical practice between USA and China. J Thorac Dis 2020;12(7):3809-3812. doi: 10.21037/ jtd.2020.04.07
2005;8:274-8.

3. Fang YR, Ma Y, Xu SH, et al. A case control study of risk factors for lung cancer. Journal of Preventive Medicine 2019;31:649-52

4. Chapman AM, Sun KY, Ruestow P, et al. Lung cancer mutation profile of EGFR, ALK, and KRAS: meta-analysis and comparison of never and ever smokers. Lung Cancer 2016;102:122-34.

5. China has achieved significant milestones in the reform of the medical and health system. Available online: http:// www.gov.cn/xinwen/2017-10/10/content_5230883.htm. Accessed on October 10, 2017.

6. Is the level of cancer treatment in the United States necessarily higher than in China? Talking about the 7-point deficiency in cancer prevention and control in China. Available online: http://dy.163.com/v2/article/detail/ EDEI5ANE0514AACD.html. Accessed on April 23, 2019.

7. Huang J, Lu J, Shen HM, et al. Application of traditional chinese medicine in malignant tumor management. Medicine and Philosophy 2019;40:69-73

8. Expert: The effectiveness of the standardized training system for Chinese residents. Available online: https:// baijiahao.baidu.com/s?id=1627448319383126533\&wfr=spi der\&for=pc. Accessed on March 8, 2019.

9. Yang JJ, Wu YL. Insight into early-phase trials for lung cancer in the United States. Chin J Cancer 2015;34:288-94.

10. Lv LN, Liu Y. Comparison and Analysis for Institutions Medical Sciences between China and America. Chinese Basic Science 2000;8:31-7. 